\title{
Comparing the Efficacy of Syngeneic Iliac and Femoral Allografts with Iliac Crest Autograft in a Rat Model of Lumbar Spinal Fusion
}

Christina Holmes ( $\nabla$ caholmes@eng.famu.fsu.edu )

Florida State University https://orcid.org/0000-0003-0736-0503

Benjamin D. Elder

Mayo Clinic Minnesota

Wataru Ishida

Johns Hopkins University School of Medicine

Alexander Perdomo Pantoja

Johns Hopkins University School of Medicine

John Locke

Johns Hopkins University School of Medicine

Ethan Cottrill

Johns Hopkins University School of Medicine

Sheng-Fu L. Lo

Johns Hopkins University School of Medicine

Timothy F. Witham

Johns Hopkins University School of Medicine

Research article

Keywords: spinal fusion, animal model, autograft, allograft, bone marrow cells

Posted Date: May 12th, 2020

DOI: https://doi.org/10.21203/rs.3.rs-27369/v1

License: (1) (1) This work is licensed under a Creative Commons Attribution 4.0 International License.

Read Full License

Version of Record: A version of this preprint was published on September 15th, 2020. See the published version at https://doi.org/10.1186/s13018-020-01936-8. 


\section{Abstract}

Background: Despite widespread use of femoral-sourced allografts in clinical spinal fusion procedures and the increasing interest in using femoral reamer-irrigator-aspirator (RIA) autograft in clinical bone grafting, few studies have examined the efficacy of femoral grafts compared to iliac crest grafts in spinal fusion. The objective of this study was to directly compare the use of autologous iliac crest with syngeneic femoral and iliac allograft bone in the rat model of lumbar spinal fusion.

Methods: Single-level bilateral posterolateral intertransverse process lumbar spinal fusion surgery was performed on Lewis rats divided into three experimental groups: iliac crest autograft; syngeneic iliac crest allograft; and syngeneic femoral allograft bone. Eight weeks postoperatively, fusion was evaluated via microCT analysis, manual palpation and histology. In vitro analysis of the colony-forming and osteogenic capacity of bone marrow cells derived from rat femurs and hips was also performed to determine whether there was a correlation with the fusion efficacy of these graft sources.

Results: Although no differences were observed between groups in CT fusion rates or fusion mass volumes, iliac allografts displayed a higher rate of bilateral fusion via manual palpation. Histologically, hip-derived grafts showed better integration with host bone than femur derived ones, likely associated with the higher concentration of osteogenic progenitor cells observed in hip-derived bone marrow.

Conclusions: This study demonstrates the feasibility of using syngeneic allograft bone in place of autograft bone within inbred rat fusion models and highlights the need for further study of femoralderived grafts in fusion.

\section{Background}

Spinal fusion is an increasingly common procedure used to treat diverse pathologies arising from spinal trauma, degenerative diseases, deformity, infection, and tumors. Although generally successful in most patients, fusion fails in up to $35 \%$ of cases, resulting in significant patient morbidity, the need for additional procedures, and increased health care costs [1]. Over the past decade, a wide range of treatment options have been explored to prevent fusion failure, or pseudarthrosis, with much of this research employing pre-clinical animal models.

The rat posterolateral spinal fusion model has become an increasingly popular experimental model to assess the efficacy of novel fusion treatments [2]. Compared to other commonly used animal models in spinal fusion research, such as rabbits, sheep, goats, pigs, dogs, and monkeys, the rat model presents a number of key advantages [3]. Rats are lower cost, facilitate shorter operation times and higherthroughput studies, and most importantly, enable more in-depth analyses of the biology underlying fusion due to a wider availability of cellular and molecular tools. Various fusion therapies have been studied in rat models, including: a range of bone graft substitute and extension materials; systemic and localized delivery of osteogenic growth factors and/or osteoporosis therapies; and, stem cell transplantation therapies [4-14]. 
As autograft iliac crest bone remains the clinical 'gold standard' in fusion procedures, many rat fusion studies employ this graft source as a control group. However, autograft iliac crest bone is limited in supply, can be difficult to harvest at a consistent volume, and its harvest leads to both additional surgical time per animal and donor site morbidity. These issues can be circumvented by employing inbred rat strains, which allow for the use of syngeneic allografts in place of autograft bone. The ability to employ syngeneic allografts also enables evaluation of the fusion efficacy of bone grafts derived from different skeletal sites. Remarkably, despite the widespread use of femoral-sourced allografts in clinical spinal fusion procedures and the increasing interest in using femoral reamer-irrigator-aspirator (RIA) autograft in clinical bone grafting procedures, the fusion efficacy of femoral- and iliac crest- derived grafts has yet to be compared in the spine [15-18]. In this study, we thus directly compared the use of autograft iliac crest bone to syngeneic femoral and iliac crest allograft bone in the rat model of posterolateral lumbar spinal fusion. Since a key element to the clinical success of autograft bone is the presence of osteogenic cells, we also performed in vitro analysis of the colony-forming and osteogenic capacity of bone marrow cells derived from rat femurs and hips to determine whether this correlated with the fusion efficacy of these graft sources.

\section{Methods}

\section{Animals}

The following study was approved by the Institutional Animal Care and Use Committee at Johns Hopkins University School of Medicine (RA14M347). Experimental animals were housed in a specific pathogenfree facility and fed a standard diet. All animals used in this study were 6-9-week female Lewis rats (100$180 \mathrm{~g})$.

\section{Surgical Procedures}

Single-level bilateral posterolateral intertransverse process lumbar spinal fusion surgery was performed, as described previously $[19,20]$, on 53 host rats divided into three experimental groups: $[A]$ iliac crest autograft $(n=16)$; [B] syngeneic iliac crest allograft $(n=19)$; and, [C] syngeneic femoral allograft bone ( $n$ $=18)$. Briefly, host rats were anesthetized via intraperitoneal $(I P)$ injection of ketamine $(36 \mathrm{mg} / \mathrm{kg})$ and xylazine (4 mg/kg). The surgical site was shaved and prepped with $70 \%$ ethanol and povidone-iodine and sterile gloves and masks were used by all surgical personnel. The surgical procedure was performed using an operating microscope or surgical loupes at $2.5 \times$ to $10 \times$ magnification. The L4 to L5 vertebral levels were identified by palpation and anatomical landmarks. A dorsal midline skin incision was made centered over the L4-L5 spinous process, and a self-retaining retractor was utilized to retract skin edges. Two paramedian fascial incisions were then made through the lumbar fascia. The intermuscular plane was established between the multifidus and longissimus muscles to expose the transverse processes of $L 4$ to $L 5$ as well as the inter-transverse membrane. Decortication of the transverse processes and lateral pars/facet joints was performed with a motorized burr. The appropriate graft was placed over the entire fusion bed space (L4 to L5) on each side of the spine. 
In the autograft group [A], the midline incision was extended to the sacrum and dissection was taken to the iliac crest on each side, and following subperiosteal dissection over the posterior aspect of the iliac crest, a small volume of corticocancellous autograft was harvested with a rongeur. In the syngeneic allograft groups, hips (the ilium down to the acetabulum) $[B]$ and femurs [C] were sterilely isolated from freshly euthanized littermate donors and placed on ice, immediately prior to fusion surgery. In most cases, harvested bone grafts were weighed on a sterile scale. In all cases, isolated bones were morselized with a rongeur prior to implantation to create a homogenous distribution of corticocancellous graft material over the fusion bed.

Fascia and skin were closed in layers with 5 - 0 absorbable sutures (Polysorb, Medtronic, Minneapolis, MN, USA). Normal saline was administered intraperitoneally after wound closure as needed. Rats were maintained on a heating pad until spontaneous ambulation was observed. Buprenorphine $(0.01 \mathrm{mg} / \mathrm{kg})$ was administered subcutaneously every 24 hours for two days. After surgery, rats were closely monitored for any sign of nerve palsy, hemiparesis, or infection as well as any changes in general condition. All animals were euthanized eight weeks post-surgery and spines were harvested.

\section{Radiographical Analysis}

Harvested lumbar spines were imaged using a nanoSPECT/CT Small Animal Imager (Mediso Medical Imaging Systems, Budapest, Hungary). The coronal CT images were evaluated by two authors in a blinded fashion. Each side of the fusion mass was graded as fused, partially fused, or non-fused based on the following criteria: 2 if robust fusion between L4-5 was observed, 1 if some narrowing of fusion mass between L4-5 was present, and 0 if there was a discontinuity of fusion mass between L4-5, and then the sum of fusion scores of both sides was calculated [21]. Axial cross sections were also generated to quantitatively calculate fusion mass volume via ImageJ software (US National Institutes of Health, Bethesda, MD) and the Volumest plugin as previously described [20, 22, 23].

\section{Manual Palpation}

Soft tissue surrounding the L3-L6 region of harvested spines was gently removed. Two blinded independent observers manually palpated the fusion site (L4-L5) to evaluate biomechanical fusion. Palpation was scored as either bilaterally fused (i.e. no segmental motion compared to the adjacent levels), or non-fused (i.e. similar segmental motion across the index level compared to the adjacent levels).

\section{Histology}

Harvested spine samples were fixed in $4 \%$ paraformaldehyde overnight, decalcified in Rapid Bone Decalcifier (American MasterTech Scientific, Lodi, California) for 8 hours, dehydrated by ethanol series $(70 \%, 95 \%, 100 \%)$, and embedded in paraffin. Serial coronal sections (10 $\mu \mathrm{m}$ thick) across the level of the fusion masses were cut, deparaffinized in xylene, and subsequently rehydrated in a descending ethanol series $(100 \%, 95 \%$, and $70 \%)$. Hematoxylin and eosin (H\&E) staining and Masson's trichrome staining were conducted to evaluate the formation of bone, cartilage, and osteoid. 


\section{Bone Marrow Cell Isolation and Culture}

Nine donor rats were euthanized and femurs and ilia were isolated, dissected and cleaned in a sterile biological safety cabinet. Bones were cut into smaller pieces, crushed using a sterile mortar and pestle, and washed several times in chilled culture medium (Dulbecco's Modified Eagle Medium (DMEM; high glucose; Gibco, USA) supplemented with 10\% Fetal Calf Serum (FCS) and 1\% (v:v) PenicillinStreptomycin) to isolate bone marrow cells. The resulting cell suspension was passed through a $100-\mu m$ nylon mesh filter and subsequently underwent hemolysis and centrifugation. Recovered nucleated cells were enumerated, re-suspended and either used in limiting dilution assays or cultured at $37^{\circ} \mathrm{C}$ in humidified air with $5 \% \mathrm{CO}_{2}$. The first media exchange was performed $\sim 72 \mathrm{~h}$ after plating, with subsequent media exchanges every 2-3 days.

\section{Limiting Dilution Colony - Forming Unit Fibroblast (CFU-F) Assay}

The frequency of mesenchymal progenitor cells within hip-derived and femur-derived bone marrow was determined via limiting dilution colony-forming unit fibroblast (CFU-F) assays. Briefly, cultures were initiated with freshly isolated bone marrow cells at densities of $3 \times 10^{5}, 1 \times 10^{5}, 3 \times 10^{4}, 2.5 \times 10^{6}$, and $5 \times$ $10^{6}$ cells/well in $96 /$ well plates in culture media, with 10 replicate wells per density per rat $(n=7$ for femur, $n=6$ for hip). On day 10 of culture, plates were fixed with methanol and stained with Crystal Violet. The total number of wells containing at least 1 fibroblastic CFU-F colony of 10 or more cells (representing at least three population doublings) at each density was enumerated using microscopic observation. CFU-F frequencies were calculated using the online ELDA tool available at http://bioinf.wehi.edu.au/software/elda/ [24].

\section{Osteogenic Differentiation Assay}

To assess the osteogenic differentiation capacity of hip-derived and femur-derived bone marrow, passage 1 (P1) cells from 8 donor rats were seeded in triplicate at a density of $50,000 \mathrm{cells} / \mathrm{cm}^{2}$ in either osteogenic media (DMEM (low glucose; Gibco, USA) supplemented with 10\% FCS, 1\% penicillinstreptomycin, $10 \mathrm{mM}$ ß-glycerophosphate (Sigma), and $50 \mu \mathrm{M}$ L-ascorbic acid-2-phosphate) or in standard culture media (as a negative control) and cultured for 21 days. Mineralization was assessed via Alizarin Red S staining. Briefly, samples were washed twice with PBS, fixed with 3.7\% formaldehyde for 20 min, washed again three times, subsequently incubated for 10 min with $40 \mathrm{mM}$ Alizarin Red S (Sigma) and then washed extensively before imaging. Subsequently, Alizarin Red S was eluted from stained cultures for quantification via incubation with $10 \%$ acetic acid at room temperature with shaking for $30 \mathrm{~min}$, followed by cell scraping and transfer to Eppendorf microcentrifuge tubes. The resulting samples were vortexed for $30 \mathrm{sec}$, heated at $85^{\circ} \mathrm{C}$ for $10 \mathrm{~min}$, incubated on ice for $5 \mathrm{~min}$, and subsequently centrifuged at $20,000 \mathrm{xg}$ for $15 \mathrm{~min}$. $200 \mathrm{ul}$ of the resulting supernatant was transferred to a new microcentrifuge tube and neutralized with 75 ul of $10 \%$ ammonium hydroxide. One hundred fifty 
microliters was transferred to a 96-well plate, and absorbance was measured at $405 \mathrm{~nm}$ using a microplate reader (PerkinElmer VICTOR3).

\section{Statistical Analysis}

In the case of three experimental groups (e.g. comparison of graft weights, fusion scores, CT volumes), intergroup comparisons of continuous variables were performed via one-way ANOVA (parametric) or Kruskal-Wallis tests (non-parametric), while categorical data sets were tested via the $\chi^{2}$ test. In the case of two experimental groups (e.g. comparison of cell yield, Alizarin Red staining), intergroup comparison was performed via paired Student's T-Test. All reported $p$ values are 2 -sided and $p$ values $<0.05$ were considered to be statistically significant. All statistical analyses were performed using GraphPad Prism 6.0 (La Jolla, CA, USA) with the exception of analysis of CFU-F frequency, which was performed using the online ELDA tool available at http://bioinf.wehi.edu.au/software/elda/ [24].

\section{Results}

\section{Fusion Assessment}

Rats recovered well from surgery and did not exhibit any significant complications. There was no significant difference among the mean pre-implantation graft weights which were $0.151 \pm 0.092 \mathrm{~g}, 0.175$ $\pm 0.064 \mathrm{~g}$ and $0.209 \pm 0.048 \mathrm{~g}$ for grafts derived from autograft hip, allograft hip, and allograft femur, respectively $(p=0.113$, Fig. $1 \mathrm{~A})$.

MicroCT imaging (Fig. 1B, 2) revealed average fusion scores of $0.5 \pm 0.5$ for the autograft group, $0.9 \pm 1.3$ for the iliac allograft group, and $0.8 \pm 0.6$ for the femoral allograft group, with no statistically significant differences $(p=0.426)$. Analysis of microCT images yielded average fusion mass volumes of $13.3 \pm 8.9$ $\mathrm{mm}^{3}$ in the autograft group, $23.2 \pm 21.6 \mathrm{~mm}^{3}$ in the iliac allograft group, and $18.0 \pm 7.2 \mathrm{~mm}^{3}$ in the femoral allograft group (Fig. 1C, 2). There were no statistically significant differences among these groups $(p=0.140)$. However, manual palpation analysis of fusion masses indicated that iliac allografts yielded the highest bilateral fusion rates with $31.6 \%$ bilaterally fused, compared to $6.3 \%$ in the autograft group, and $5.6 \%$ in the femoral allograft groups (Fig. 1D) $(p=0.043)$.

Histology revealed that the iliac auto- and allo- graft groups displayed zones of osteointegration between grafts and both transverse processes more often than the femoral allograft group (Fig. 3). Increased osteoid deposition, number of osteoblasts, and osteocytes were observed within the fusion masses of the hip-derived graft groups, while the femur-derived graft group exhibited significant osteoid deposition but lower cellularity. Fusion masses from the hip-derived graft groups also showed more extensive areas of bone marrow than those from the femoral allograft group.

\section{Cellular Analysis}


Whole femurs yielded more nucleated cells than ilia $\left(5.73 \pm 1.86 \times 10^{7}\right.$ vs. $4.64 \pm 1.07 \times 10^{7}$ cells, $p=$ 0.030; Fig. 4A). However, limiting dilution CFU-F analysis demonstrated a higher frequency of mesenchymal progenitors in hip-derived than femur-derived bone marrow cell populations $(1 / 85,292$ cells vs. $1 / 258,838$ cells, $p=0.015$; Fig. 4B). Hip- and femur- derived bone marrow mesenchymal progenitors displayed similar osteogenic differentiation capacity, as Alizarin Red $S$ staining indicated no significant differences $(p=0.469 ;$ Fig. $4 C, D)$.

\section{Discussion}

This is one of the first studies to directly compare the efficacy of femoral vs. iliac allograft, as well as autograft vs. allograft bone, in a rat spinal fusion model. Although, no statistically significant differences were observed between grafting groups in terms of initial graft weight, CT fusion score, or fusion mass volume, iliac allografts were found to yield a significantly higher rate of bilateral fusion via manual palpation. The higher palpation fusion rate observed in the iliac allograft group compared to the corresponding iliac autograft group was potentially related to the higher fusion mass volume $(23.2 \pm 21.6$ $\mathrm{mm}^{3}$ vs. $13.3 \pm 8.9 \mathrm{~mm}^{3}$ ) shown in the allograft group, even though this increase was not statistically significant due to high variability. Another probable contributing factor is the slight difference in overall graft compositions, as the syngeneic hip allografts were derived from the whole ilium (including elements of the acetabulum), while the autografts consisted of the iliac crest alone, thus leading to possible differences in cortical-to-trabecular ratios as well as total cellular composition and concentration. Interestingly, the greater palpation scores seen in the allograft hip group compared to the femoral group were reflected in the histological observations of better integration with host bone and increased osteoblasts and osteocytes in hip-derived fusion masses in contrast to those derived from femoral grafts.

The histological differences in the study were echoed in our in vitro analyses. Hip-derived bone marrow cells exhibited a higher CFU-F frequency than femur-derived populations, thus indicating a higher concentration of the osteogenic progenitor cells than can differentiate into osteoblasts and osteocytes. This increase in hip-derived mesenchymal progenitor cell frequency also likely contributed to the improved integration with host bone observed in hip graft-derived fusion masses, as mesenchymal progenitor cells are known to recruit host cell migration via paracrine mechanisms and improve bone repair.[25] The bone-forming capacity of the hip- and femur- derived bone marrow progenitor cells, however, was found to be similar. There were no differences in osteogenic differentiation in vitro between P1 bone marrow cells derived from either bone marrow population, and histology indicated that both hipand femur- derived graft groups yielded osteoid deposition within fusion masses in vivo.

The comparable CT fusion scores observed in this study between autograft and syngeneic allograft bone, reflect findings in several clinical fusion studies which also used radiographic or CT measures of fusion to compare autograft to frozen allograft $[26,27]$. For example, recent meta-analyses by several groups have found comparable lumbar fusion rates between patients treated with allograft and autograft iliac crest bone, with no significant differences in disability or pain scores [28, 29]. As in previous studies, the discrepancy between CT and manual palpation scores in our study further demonstrates that importance 
of employing multiple modalities to assess fusion, as relying on radiographic diagnosis of pseudarthrosis alone may lead to false-positive or false-negative results.

Although autologous iliac crest bone remains the "gold standard", femoral- sourced grafts have been commonly used in spinal fusion and bone grafting procedures. In clinical fusion procedures, femoral ring and femoral dowel allografts have been widely employed as osteoconductive structural grafts in interbody procedures [30-34], while femoral head allograft has been successfully used in interbody [35$38]$, and posterolateral lumbar procedures $[15,39]$. With increasing interest in the use of femoral reamerirrigator-aspirator (RIA) bone autograft, a number of clinical studies have recently compared the efficacy of RIA and iliac crest autograft in nonunion, posttraumatic segmental bone defect, or ankle fusion patients and have observed comparable [40-43], or increased union rates and times to union [44]. Femoral RIA autograft has also been successfully used in clinical interbody and posterolateral fusion procedures $[45,46]$. Our study, which is the first to directly compare femur- and hip-derived bone grafts in spinal fusion, suggests that femur-derived grafts at least perform comparably to hip-derived grafts in rats in terms of $\mathrm{CT}$ fusion measures.

Since a key element to the clinical success of autograft bone is the presence of osteogenic cells, we compared the colony-forming and osteogenic capacity of bone marrow cells derived from the femur and ilium. Similar to our observations, previous animal studies in dogs and pigs observed higher CFU-F frequency in bone marrow derived from the iliac crest than from the femur $[47,48]$. Comparisons of marrow-derived mesenchymal cells from human ilia and femurs, however, have revealed conflicting results, with some yielding similar properties [49-54], while others have observed higher concentrations of osteogenic progenitors in marrow from the iliac crest [55,56], or from the femur $[57,58]$. These seemingly contradictory results may largely be due to differences in study design, particularly: the isolation methods used; the specific regions of the femur and hip from which cells are isolated, e.g. proximal vs. distal femur, iliac crest vs. anterior superior iliac spine; and, the patient populations under investigation.

One of the key limitations of this study was the high variability observed, particularly in the CT fusion scores and fusion volumes. While it is possible that subtle differences in surgical technique may have influenced this variation, the range in age and weight of the animals used as donors and hosts is a more likely contributing factor, as our previous meta-analysis of rat fusion models showed an association between animal age and/or weight and fusion outcomes [2]. Another potential source of variability, especially in the allograft groups, is the possibility that there were slight within group differences in implanted graft composition; for example, one animal may have received more of the epiphysis portion and another more of the diaphysis portion of the femur. Studies in humans, for example, have shown that the proximal femur contains bone marrow with a higher concentration of osteogenic CFU-F than the distal femur [54]. Although the observed rates of fusion in this study were low compared to several previous rat studies, our allograft hip fusion rate was comparable to the only other study to use freshly isolated iliac allograft, which observed manual palpation fusion rates of $~ 40 \%$ in Sprague-Dawley rats [59]. Possible reasons for the lower fusion rates observed in this study include: the stringency of our 
fusion assessment criteria (i.e. only counting solid bilateral fusion) compared to previous studies; the amount of bone graft that we implanted may not have been sufficient to yield higher fusion rates; and rat strain differences in bone healing. In order to optimize the syngeneic allograft rat lumbar fusion model, future studies will control more carefully for these factors, using a tighter age and weight range in donor and host rats, and will examine: increasing volumes of bone graft; site-specific bone graft regions (i.e. epiphysis vs. diaphysis); and, a wider range of donor bone types.

\section{Conclusions}

Despite limitations, this study demonstrates that employing inbred rat strains enables syngeneic allograft bone to be used successfully in place of autograft bone in lumbar fusion studies, thus reducing donor site morbidity and surgical time in host animals. Furthermore, syngeneic allograft was shown to perform comparably or superiorly to autograft bone in the rat fusion model. More importantly, as the first study to compare freshly isolated hip and femur-derived bone grafts in a spinal fusion model, we demonstrated that while femoral grafts exhibited similar CT fusion rates and fusion mass volumes, iliac grafts displayed a higher rate of bilateral fusion via manual palpation. In our rat model, this increase in mechanical fusion was associated with superior histological integration with host bone, which was likely connected to the higher observed concentration of osteogenic progenitor cells in hip-derived bone marrow. These results suggest the need for further comparison of femur-derived grafts, such as RIA femoral autograft, and iliac crest grafts in the context of spinal fusion.

\section{Abbreviations}

CFU-F

colony-forming unit fibroblast

CT

computed tomography

DMEM

Dulbecco's Modified Eagle Medium

PBS

phosphate buffered saline

P1

passage 1

RIA

reamer-irrigator-aspirator

\section{Declarations}

Ethics approval and consent to participate 
All animal studies were approved by the Institutional Animal Care and Use Committee at Johns Hopkins University School of Medicine (RA14M347).

Consent for publication

Not applicable

Availability of data and materials

The datasets used and/or analyzed during the current study are available from the corresponding author on reasonable request.

Competing interests

The authors declare that they have no competing interests.

Funding

The research performed in this study was supported by funding from The Gordon and Marilyn Macklin Foundation.

Authors' contributions

$\mathrm{CH}$ designed the study, performed cell isolations and in vitro analyses, analyzed data (including statistical analyses), and wrote the manuscript.

BE designed the study, performed animal surgeries, CT analyses and manual palpation analyses, and edited the manuscript

WI performed animal surgeries, CT analyses and manual palpation analyses

AP performed histology and related analyses

JL assisted in animal surgeries, cell isolations, animal dissections and data recording

EC performed histology and related analyses

SFL performed animal surgeries, CT analyses and manual palpation analyses

TW oversaw entire study and all personnel, edited manuscript, designed the study

Acknowledgements

Not applicable.

\section{References}


1. Steinmann JC, Herkowitz HN. Pseudarthrosis of the spine. Clin Orthop Relat Res [Internet]. JB LIPPINCOTT CO; 1992;80-90. Available from: http://www.ncbi.nlm.nih.gov/pubmed/1395317.

2. Ishida W, Elder BD, Holmes C, Lo S-FL, Witham TF. Variables Affecting Fusion Rates in the Rat Posterolateral Spinal Fusion Model with Autogenic/Allogenic Bone Grafts: A Meta-analysis. Ann Biomed Eng [Internet]. 2016 [cited 2016 Dec 1];44:3186-201. Available from: http://www.ncbi.nlm.nih.gov/pubmed/27473706.

3. Drespe IH, Polzhofer GK, Turner AS, Grauer JN. Animal models for spinal fusion. Spine J [Internet]. [cited 2014 Mar 20];5:209S-216S. Available from: http://www.ncbi.nlm.nih.gov/pubmed/16291115.

4. Brecevich AT, Kiely PD, Yoon BV, Nguyen JT, Cammisa FP, Abjornson C. Efficacy comparison of Accell Evo3 and Grafton demineralized bone matrix putties against autologous bone in a rat posterolateral spine fusion model. Spine J [Internet]. 2017 [cited 2019 Nov 18];17:855-62. Available from: http://www.ncbi.nlm.nih.gov/pubmed/28126356.

5. Hayashi T, Lord EL, Suzuki A, Takahashi S, Scott TP, Phan K, et al. A comparison of commercially available demineralized bone matrices with and without human mesenchymal stem cells in a rodent spinal fusion model. J Neurosurg Spine [Internet]. 2016 [cited 2019 Nov 18];25:133-7. Available from: http://www.ncbi.nlm.nih.gov/pubmed/26967986.

6. Koerner JD, Yalamanchili P, Munoz W, Uko L, Chaudhary SB, Lin SS, et al. The effects of local insulin application to lumbar spinal fusions in a rat model. Spine J [Internet]. 2013 [cited $2019 \mathrm{Nov}$ 18];13:22-31. Available from: https://linkinghub.elsevier.com/retrieve/pii/S1529943012014374.

7. Inoue G, Uchida K, Matsushita O, Fujimaki H, Saito W, Miyagi M, et al. Effect of Freeze-Dried Allograft Bone With Human Basic Fibroblast Growth Factor Containing a Collagen-Binding Domain From Clostridium histolyticum Collagenase on Bone Formation After Lumbar Posterolateral Fusion Surgery in Rats. Spine (Phila Pa 1976) [Internet]. 2017 [cited 2019 Nov 18];42:E995-1001. Available from: http://www.ncbi.nlm.nih.gov/pubmed/28098745.

8. Park B-H, Song K-J, Yoon SJ, Park HS, Jang KY, Zhou L, et al. Acceleration of spinal fusion using COMP-angiopoietin 1 with allografting in a rat model. Bone [Internet]. 2011 [cited 2019 Nov 18];49:447-54. Available from: http://www.ncbi.nlm.nih.gov/pubmed/21658484.

9. Park SB, Kim CH, Hong M, Yang H-J, Chung CK. Effect of a selective estrogen receptor modulator on bone formation in osteoporotic spine fusion using an ovariectomized rat model. Spine J [Internet]. 2016 [cited 2019 Nov 18];16:72-81. Available from:

http://www.ncbi.nlm.nih.gov/pubmed/26343247.

10. http://doi.wiley.com/10.1002/jor.22763

Yasen M, Li X, Jiang L, Yuan W, Che W, Dong J. Effect of zoledronic acid on spinal fusion outcomes in an ovariectomized rat model of osteoporosis. J Orthop Res [Internet]. 2015 [cited 2019 Nov 18];33:1297-304. Available from: http://doi.wiley.com/10.1002/jor.22763.

11. Bae HW, Zhao L, Kanim LEA, Wong P, Marshall D, Delamarter RB. Bone marrow enhances the performance of rhBMP-2 in spinal fusion: a rodent model. J Bone Joint Surg Am [Internet]. 2013 
[cited 2019 Nov 18];95:338-47. Available from: https://insights.ovid.com/crossref?an=00004623201302200-00009.

12. Miyazaki M, Zuk PA, Zou J, Yoon SH, Wei F, Morishita Y, et al. Comparison of Human Mesenchymal Stem Cells Derived From Adipose Tissue and Bone Marrow for Ex Vivo Gene Therapy in Rat Spinal Fusion Model. Spine (Phila Pa 1976) [Internet]. 2008 [cited 2019 Nov 18];33:863-9. Available from: http://www.ncbi.nIm.nih.gov/pubmed/18404105.

13. Seo HS, Jung JK, Lim M-H, Hyun DK, Oh N-S, Yoon SH. Evaluation of Spinal Fusion Using Bone Marrow Derived Mesenchymal Stem Cells with or without Fibroblast Growth Factor-4. J Korean Neurosurg Soc [Internet]. 2009 [cited 2019 Nov 18];46:397-402. Available from: http://www.ncbi.nlm.nih.gov/pubmed/19893733.

14. Chung CG, James AW, Asatrian G, Chang L, Nguyen A, Le K, et al. Human Perivascular Stem CellBased Bone Graft Substitute Induces Rat Spinal Fusion. Stem Cells Transl Med [Internet]. 2014 [cited 2019 Nov 18];3:1231-41. Available from: http://www.ncbi.nlm.nih.gov/pubmed/25154782.

15. Gibson S, McLeod I, Wardlaw D, Urbaniak S. Allograft versus autograft in instrumented posterolateral lumbar spinal fusion: a randomized control trial. Spine (Phila Pa 1976) [Internet]. 2002 [cited 2019 Sep 24];27:1599-603. Available from: http://www.ncbi.nlm.nih.gov/pubmed/12163718.

16. Urrutia J, Molina M. Fresh-frozen femoral head allograft as lumbar interbody graft material allows high fusion rate without subsidence. Orthop Traumatol Surg Res [Internet]. Elsevier Masson; 2013 [cited 2018 Apr 22];99:413-8. Available from: https://www-sciencedirectcom.ezp.welch.jhmi.edu/science/article/pii/S1877056813000674?via\%3Dihub.

17. Brown DA, Mallory GW, Higgins DM, Abdulaziz M, Huddleston PM, Nassr A, et al. A cost-effective method for femoral head allograft procurement for spinal arthrodesis: an alternative to commercially available allograft. Spine (Phila Pa 1976) [Internet]. 2014 [cited 2019 Sep 24];39:E902-6. Available from: http://www.ncbi.nlm.nih.gov/pubmed/24827513.

18. Madison RD, Nowotarski PJ. The Reamer-Irrigator-Aspirator in Nonunion Surgery. Orthop Clin North Am [Internet]. 2019 [cited 2019 Oct 9];50:297-304. Available from:

http://www.ncbi.nlm.nih.gov/pubmed/31084831.

19. Grauer JN, Bomback DA, Lugo R, Troiano NW, Patel TC, Friedlaender GE. Posterolateral lumbar fusions in athymic rats: characterization of a model. Spine J [Internet]. [cited 2014 Sep 23];4:281-6. Available from: http://www.ncbi.nlm.nih.gov/pubmed/15125850.

20. Ishida W, Perdomo-Pantoja A, Elder BD, Locke J, Holmes C, Witham TF, et al. Effects of Intraoperative Intrawound Antibiotic Administration on Spinal Fusion: A Comparison of Vancomycin and Tobramycin in a Rat Model. J Bone Joint Surg Am [Internet]. 2019 [cited 2019 Oct 9];101:1741-9. Available from: http://www.ncbi.nlm.nih.gov/pubmed/31577679.

21. $10.1007 / \mathrm{s} 00198-013-2385-7$

Qiu Z, Wei L, Liu J, Sochacki KR, Liu X, Bishop C, et al. Effect of intermittent PTH (1-34) on posterolateral spinal fusion with iliac crest bone graft in an ovariectomized rat model. Osteoporos Int 
[Internet]. Springer London; 2013 [cited 2019 Nov 18];24:2693-700. Available from: http://link.springer.com/10.1007/s00198-013-2385-7.

22. Lina IA, Ishida W, Liauw JA, Lo SL, Elder BD, Perdomo-Pantoja A, et al. A mouse model for the study of transplanted bone marrow mesenchymal stem cell survival and proliferation in lumbar spinal fusion. Eur Spine J [Internet]. 2019 [cited 2019 Oct 9];28:710-8. Available from: http://www.ncbi.nlm.nih.gov/pubmed/30511246.

23. Lina IA, Puvanesarajah V, Liauw JA, Lo S-FL, Santiago-Dieppa DR, Hwang L, et al. Quantitative study of parathyroid hormone (1-34) and bone morphogenetic protein-2 on spinal fusion outcomes in a rabbit model of lumbar dorsolateral intertransverse process arthrodesis. Spine (Phila Pa 1976) [Internet]. 2014 [cited 2014 Mar 26];39:347-55. Available from: http://www.ncbi.nlm.nih.gov/pubmed/24365898.

24. Hu Y, Smyth GK. ELDA: Extreme limiting dilution analysis for comparing depleted and enriched populations in stem cell and other assays. J Immunol Methods. 2009;347:70-8.

25. Tortelli F, Tasso R, Loiacono F, Cancedda R. The development of tissue-engineered bone of different origin through endochondral and intramembranous ossification following the implantation of mesenchymal stem cells and osteoblasts in a murine model. Biomaterials [Internet]. 2010 [cited 2019 Oct 10];31:242-9. Available from: http://www.ncbi.nlm.nih.gov/pubmed/19796807.

26. Kirzner N, Hilliard L, Martin C, Quan G, Liew S, Humadi A. Bone graft in posterior spine fusion for adolescent idiopathic scoliosis: a meta-analysis. ANZ J Surg [Internet]. 2018 [cited 2019 Sep 24];88:1247-52. Available from: http://www.ncbi.nIm.nih.gov/pubmed/29763982.

27. Miller LE, Block JE. Safety and effectiveness of bone allografts in anterior cervical discectomy and fusion surgery. Spine (Phila Pa 1976) [Internet]. 2011 [cited 2019 Sep 24];36:2045-50. Available from: http://www.ncbi.nlm.nih.gov/pubmed/21304437.

28. Liao Z, Wang C-H, Cui W-L. Comparison of Allograft and Autograft in Lumbar Fusion for Lumbar Degenerative Diseases: A Systematic Review. J Invest Surg [Internet]. 2016 [cited 2019 Sep 24];29:373-82. Available from: http://www.ncbi.nlm.nih.gov/pubmed/27064603.

29. Tuchman A, Brodke DS, Youssef JA, Meisel H-J, Dettori JR, Park J-B, et al. Iliac Crest Bone Graft versus Local Autograft or Allograft for Lumbar Spinal Fusion: A Systematic Review. Glob spine J [Internet]. 2016 [cited 2019 Sep 24];6:592-606. Available from: http://www.ncbi.nlm.nih.gov/pubmed/27556001.

30. Phan K, Mobbs RJ. Evolution of Design of Interbody Cages for Anterior Lumbar Interbody Fusion. Orthop. Surg. Sociedade Brasileira de Matematica Aplicada e Computacional; 2016. p. 270-7.

31. Thalgott JS, Fogarty ME, Giuffre JM, Christenson SD, Epstein AK, Aprill C. A prospective, randomized, blinded, single-site study to evaluate the clinical and radiographic differences between frozen and freeze-dried allograft when used as part of a circumferential anterior lumbar interbody fusion procedure. Spine (Phila Pa 1976) [Internet]. 2009 [cited 2019 Sep 24];34:1251-6. Available from: http://www.ncbi.nlm.nih.gov/pubmed/19412139. 
32. Vanderschot P, Caluwe G, Lateur L, Broos P. The use of "hybrid" allografts in the treatment of fractures of the thoracolumbar spine: First experience. Eur Spine J. 2001;10:64-8.

33. Chotivichit A, Fujita T, Wong T-H, Kostuik JP, Sieber AN. Role of femoral ring allograft in anterior interbody fusion of the spine. J Orthop Surg (Hong Kong) [Internet]. 2001 [cited 2019 Sep 24];9:1-5. Available from: http://www.ncbi.nlm.nih.gov/pubmed/12118123.

34. Lekovic GP, Han PP, Kenny KJ, Dickman CA. Bone dowels in anterior lumbar interbody fusion. J Spinal Disord Tech. 2007;20:374-9.

35. Urrutia J, Molina M. Fresh-frozen femoral head allograft as lumbar interbody graft material allows high fusion rate without subsidence. Orthop Traumatol Surg Res [Internet]. 2013 [cited 2015 Aug 26];99:413-8. Available from:

http://www.sciencedirect.com/science/article/pii/S1877056813000674.

36. Bendo JA, Spivak JM, Neuwirth MG, Chung P. Use of the anterior interbody fresh-frozen femoral head allograft in circumferential lumbar fusions. J Spinal Disord [Internet]. 2000 [cited 2019 Sep 24];13:144-9. Available from: http://www.ncbi.nlm.nih.gov/pubmed/10780690.

37. Mirovsky Y, Halperin N, Anekstein Y, Neuwirth MG. Good results of circumferential spine fusion in smokers, using autograft and allograft. Cell Tissue Bank [Internet]. 2002 [cited 2019 Sep 24];3:16973. Available from: http://www.ncbi.nlm.nih.gov/pubmed/15256878.

38. Liao J-C, Niu C-C, Chen W-J, Chen L-H. Polyetheretherketone (PEEK) cage filled with cancellous allograft in anterior cervical discectomy and fusion. Int Orthop [Internet]. 2008 [cited 2019 Sep 24];32:643-8. Available from: http://www.ncbi.nlm.nih.gov/pubmed/17639386.

39. Brown DA, Mallory GW, Higgins DM, Abdulaziz M, Huddleston PM, Nassr A, et al. A Cost-effective Method for Femoral Head Allograft Procurement for Spinal Arthrodesis. Spine (Phila Pa 1976) [Internet]. 2014 [cited 2018 Apr 19];39:E902-6. Available from: http://www.ncbi.nlm.nih.gov/pubmed/24827513.

40. Dawson J, Kiner D, Gardner li W, Swafford R, Nowotarski PJ. The Reamer-Irrigator-Aspirator as a Device for Harvesting Bone Graft Compared With Iliac Crest Bone Graft: Union Rates and Complications Level of Evidence: Therapeutic Level I. See Instructions for Authors for a complete description of levels of evidence. J Orthop Trauma. 2014;28:584-90.

41. Myeroff C, Archdeacon M. Autogenous bone graft: Donor sites and techniques. J. Bone Jt. Surg. Ser. A. Journal of Bone and Joint Surgery Inc.; 2011. p. 2227-36.

42. Masquelet A-C, Benko PE, Mathevon H, Hannouche D, Obert L. French Society of Orthopaedics and Traumatic Surgery (SoFCOT). Harvest of cortico-cancellous intramedullary femoral bone graft using the Reamer-Irrigator-Aspirator (RIA). Orthop Traumatol Surg Res [Internet]. 2012 [cited 2019 Sep 24];98:227-32. Available from: http://www.ncbi.nlm.nih.gov/pubmed/22402294.

43. Le Baron M, Vivona J-P, Maman P, Volpi R, Flecher X. Can the Reamer/Irrigator/Aspirator System replace anterior iliac crest grafting when treating long bone nonunion? Orthop Traumatol Surg Res [Internet]. 2019 [cited 2019 Sep 24];105:529-33. Available from:

http://www.ncbi.nlm.nih.gov/pubmed/30885818. 
44. Nodzo SR, Kaplan NB, Hohman DW, Ritter CA. A radiographic and clinical comparison of reamerirrigator-aspirator versus iliac crest bone graft in ankle arthrodesis. Int Orthop Springer Verlag. 2014;38:1199-203.

45. 10.1227/01.neu.0000317390.21927.ad

Nichols TA, Sagi HC, Weber TG, Guiot BH. An alternative source of autograft bone for spinal fusion: the femur: technical case report. Neurosurgery [Internet]. 2008 [cited 2018 Apr 24];62:E179; discussion E179. Available from: https://academic.oup.com/ons/articlelookup/doi/10.1227/01.neu.0000317390.21927.ad.

46. Rauck RC, Fisk E, Stammen KL, Yu E, Khan SN. Reamer-irrigator-aspirator for autologous bone graft in spinal fusion: An alternative to conventional bone graft substitutes. Curr Orthop Pract Lippincott Williams Wilkins. 2016;27:564-9.

47. $10.3727 / 096368912 X 636821$

Volk SW, Wang Y, Hankenson KD. Effects of Donor Characteristics and Ex Vivo Expansion on Canine Mesenchymal Stem Cell Properties: Implications for MSC-Based Therapies. Cell Transplant [Internet]. 2012 [cited 2018 Apr 20];21:2189-200. Available from: http://dx.doi.org/10.3727/096368912X636821.

48. McDaniel JS, Antebi B, Pilia M, Hurtgen BJ, Belenkiy S, Necsoiu C, et al. Quantitative Assessment of Optimal Bone Marrow Site for the Isolation of Porcine Mesenchymal Stem Cells. Stem Cells Int [Internet]. Hindawi Limited; 2017 [cited 2018 Apr 20];2017:1836960. Available from: http://www.ncbi.nlm.nih.gov/pubmed/28539939.

49. Sanchez-Guijo FM, Blanco JF, Cruz G, Muntion S, Gomez M, Carrancio S, et al. Multiparametric comparison of mesenchymal stromal cells obtained from trabecular bone by using a novel isolation method with those obtained by iliac crest aspiration from the same subjects. Cell Tissue Res. 2009;336:501-7.

50. Uppal HS, Peterson BE, Misfeldt ML, Della Rocca GJ, Volgas DA, Murtha YM, et al. The viability of cells obtained using the Reamer-Irrigator-Aspirator system and in bone graft from the iliac crest. Bone Joint J [Internet]. 2013 [cited 2018 Apr 24];95-B:1269-74. Available from: http://www.ncbi.nlm.nih.gov/pubmed/23997144.

51. Prall WC, Saller MM, Scheumaier A, Tucholski T, Taha S, Böcker W, et al. Proliferative and osteogenic differentiation capacity of mesenchymal stromal cells: Influence of harvesting site and donor age. Injury [Internet]. 2018 [cited 2019 Sep 24];49:1504-12. Available from: http://www.ncbi.nlm.nih.gov/pubmed/29941285.

52. Cox G, Boxall SA, Giannoudis PV, Buckley CT, Roshdy T, Churchman SM, et al. High abundance of CD271 + multipotential stromal cells (MSCs) in intramedullary cavities of long bones. Bone. 2012;50:510-7.

53. Churchman SM, Kouroupis D, Boxall SA, Roshdy T, Tan HB, McGonagle D, et al. Yield optimisation and molecular characterisation of uncultured CD271 + mesenchymal stem cells in the Reamer 
Irrigator Aspirator waste bag. Eur Cell Mater [Internet]. 2013 [cited 2019 Sep 24];26:252-62. Available from: http://www.ncbi.nlm.nih.gov/pubmed/24338347.

54. Ghebes CA, Braham MVJ, Zeegers AVCM, Renard AJS, Fernandes H, Saris DBF. Means of enhancing bone fracture healing: Optimal cell source, isolation methods and acoustic stimulation. BMC Biotechnol. BioMed Central Ltd.; 2016;16.

55. Hyer CF, Berlet GC, Bussewitz BW, Hankins T, Ziegler HL, Philbin TM. Quantitative Assessment of the Yield of Osteoblastic Connective Tissue Progenitors in Bone Marrow Aspirate from the lliac Crest, Tibia, and Calcaneus. J Bone Jt Surg [Internet]. 2013 [cited 2015 Jul 6];95:1312. Available from: http://www.ncbi.nlm.nih.gov/pubmed/23864180.

56. Davies BM, Snelling SJB, Quek L, Hakimi O, Ye H, Carr A, et al. Identifying the optimum source of mesenchymal stem cells for use in knee surgery. J Orthop Res [Internet]. 2017 [cited 2018 Apr 17];35:1868-75. Available from: http://www.ncbi.nIm.nih.gov/pubmed/27935105.

57. Henrich D, Seebach C, Sterlepper E, Tauchmann C, Marzi I, Frank J. RIA reamings and hip aspirate: a comparative evaluation of osteoprogenitor and endothelial progenitor cells. Injury [Internet]. 2010 [cited 2015 Sep 2];41 Suppl 2:S62-8. Available from: http://www.sciencedirect.com/science/article/pii/S0020138310700127.

58. Henrich D, Nau C, Kraft SB, Zollfrank M, Kontradowitz K, Oppermann E, et al. Effect of the harvest procedure and tissue site on the osteogenic function of and gene expression in human mesenchymal stem cells. Int J Mol Med Spandidos Publications. 2016;37:976-88.

59. Park B-H, Song K-J, Yoon SJ, Park HS, Jang KY, Zhou L, et al. Acceleration of spinal fusion using COMP-angiopoietin 1 with allografting in a rat model. Bone [Internet]. 2011 [cited 2013 Oct 23];49:447-54. Available from:

http://www.sciencedirect.com/science/article/pii/S875632821101009X.

\section{Figures}



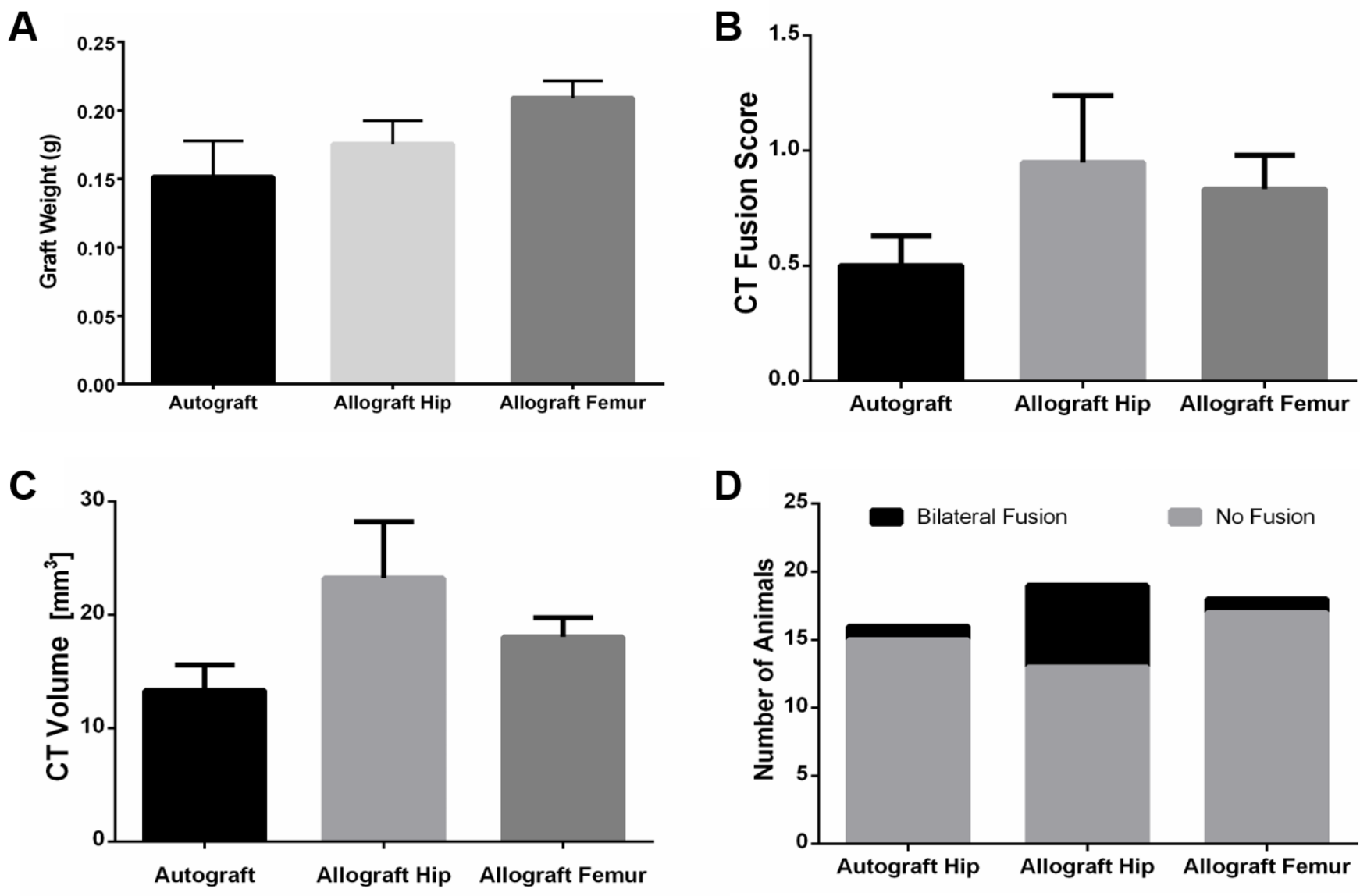

\section{Figure 1}

Fusion assessment. Comparisons of: (A) Pre-implantation graft weight, (B) CT fusion score, (C) CT volume of fusion mass, and (D) Number of fused animals via manual palpation. CT fusion score was calculated as follows: each side was separately rated as 2 if robust fusion between L4- 5 was observed, 1 if some narrowing of fusion mass between L4-5 was present, and 0 if there was a significant discontinuity of fusion mass, and then the sum of fusion scores of both sides was calculated. CT volume of fusion mass was calculated using the Volumest plug-in for Image J. Animals were scored via manual palpation as bilaterally fused (little to no motion across the operated joint), or non-fused (no reduced motion across the operated joint compared to the next upper level). Data presented as mean $\pm \mathrm{SEM}$. For graft weight: iliac crest autograft ( $n=12)$; syngeneic allograft hip ( $n=14)$; and, syngeneic allograft femur $(n=14)$, For all other assessments: iliac crest autograft $(n=16)$; syngeneic allograft hip ( $n=19)$; and, syngeneic allograft femur $(n=18)$. 

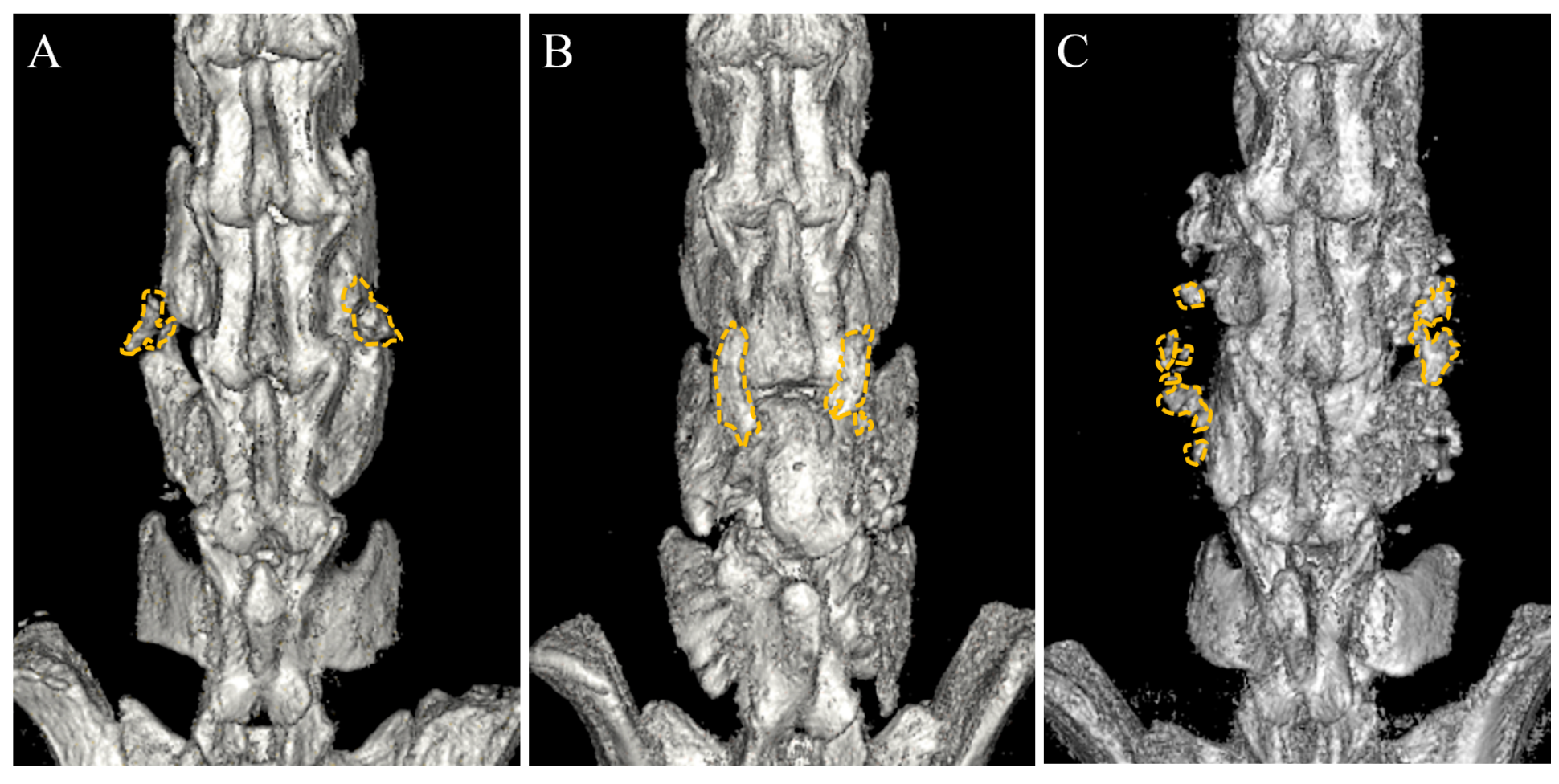

Figure 2

Representative renderings of $\mu \mathrm{CT}$ images. Autograft hip (A, left), allograft hip (B, center), and allograft femur ( $C$, right) grafting groups. Bone formation in the intertransverse space was seen in each experimental groups (yellow dashes surrounding only the newly formed bone located in the area between transverse processes). Although allograft hip (B) yielded higher fusion mass volumes, this difference was not statistically significant. Hip-derived fusions tended to appear as single intertransverse masses, while femoral allograft exhibited bone formation with a scattered pattern. 

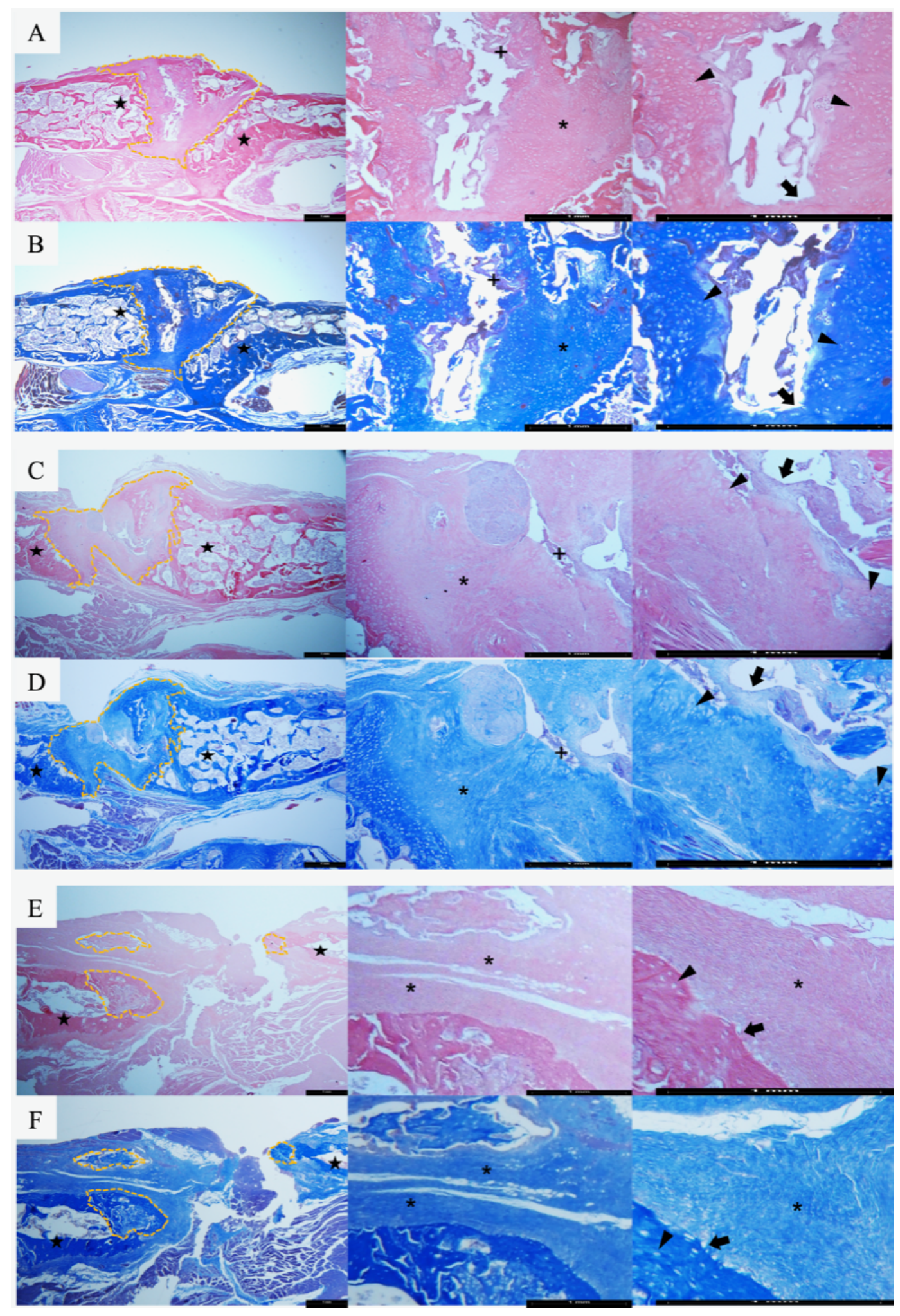

\section{Figure 3}

Representative histological images of fusion masses. Hematoxylin-eosin (A, C, E) and Masson's trichrome (B, D, F) staining (2.5X, 10X and 20X magnification, respectively) of representative fusion areas (yellow dashed lines) from autograft hip (A, B), allograft hip (C, D), and allograft femur (E, F) groups. Unlike the allograft femur group (E, F), fusion masses arising from hip-derived grafts $(A, B, C, D)$ exhibited bone formation on both adjacent transverse processes (stars). Within the intertransverse space in hip-derived 
graft groups (A, B, C, D), we observed bridging osteoid $\left(^{\star}\right)$ with a high number of osteoblasts on the surface (black arrows) and abundant osteocytes within lacunae (black arrowheads), as well as incipient bone marrow (+) in the center of the fusion masses. Black bar in all images represents $1 \mathrm{~mm}$.
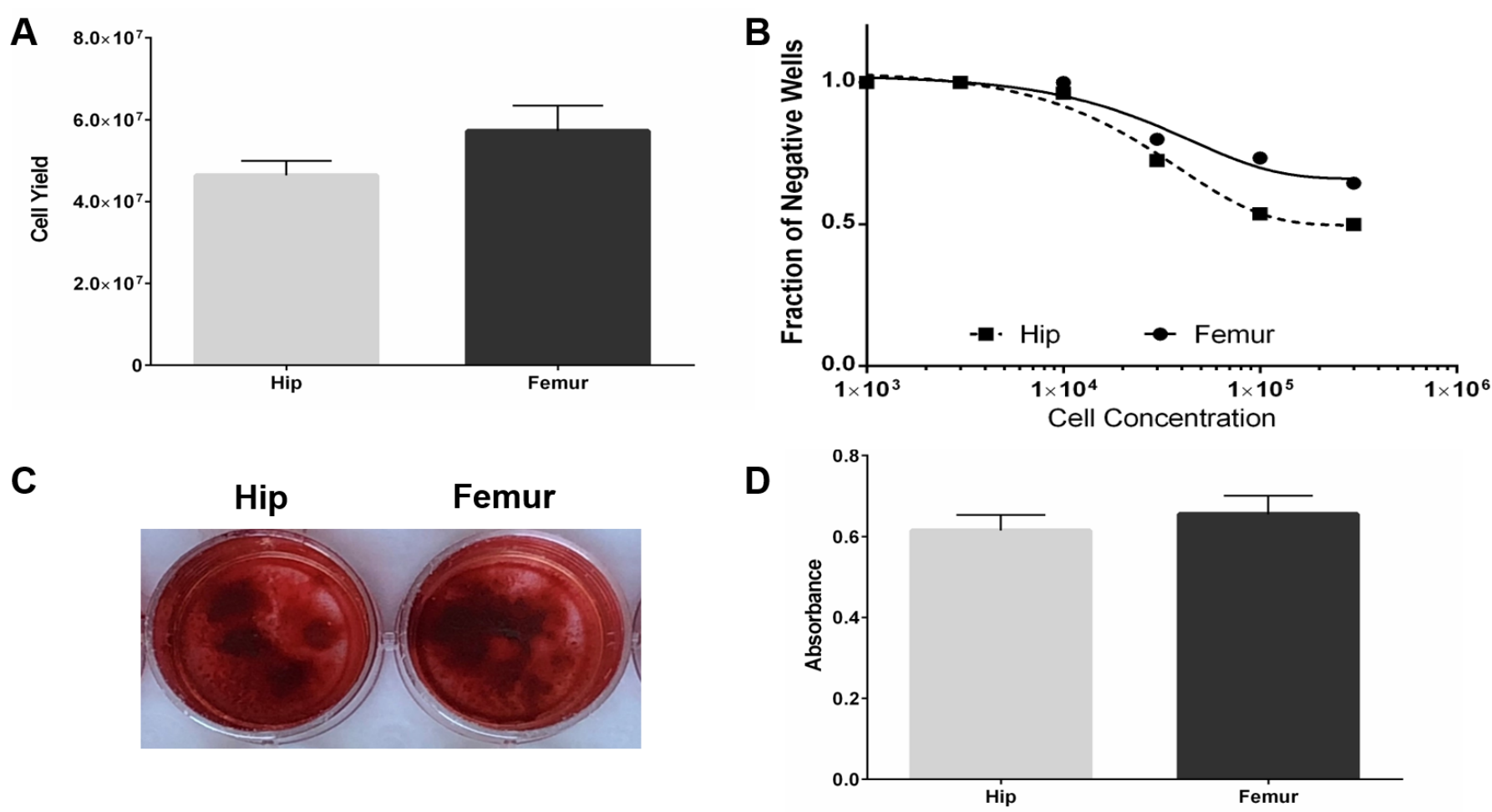

\section{Figure 4}

Cellular Analyses. (A) Total nucleated cell yield from hips (grey bar) and femurs (black bar) (n=9). (B) Limiting dilution analysis of osteogenic progenitor cells within bone marrow isolated from hips (squares) and femurs (circles). The fraction of wells without colony-forming unit fibroblast (CFU-F) colonies was plotted against the number of cells inoculated. Colonies were evaluated on day 10 ( $n=7$ for femur, $n=6$ for hip). (C) Mineralization of hip-derived (left) and femur-derived (right) cells was qualitatively assessed via Alizarin Red (AR) staining and representative images are presented. Passage 1 cells were cultured in osteogenic media for 28 days. (D) Quantification of AR staining intensity (after solubilization) from hipderived (grey bar) and femur-derived (black bar) osteogenic cultures $(n=8)$. Data presented as mean \pm SEM. 